\title{
Reusable cysteine-ferrite-based magnetic nanopowders for removal of lead ions from water
}

\author{
Alex Fabiano Cortez Campos ${ }^{a *}$ (D), Priscila Ferreira Reis ${ }^{a}$, João Victor Cequine Mendonça Neiva ${ }^{b}$, \\ Ana Alice Andrade Meireles Guerra ${ }^{b}$, Cynara Kern ${ }^{a}$, Mauro Francisco Pinheiro da Silva ${ }^{a}$, \\ Franciscarlos Gomes da Silva, ${ }^{a, c}$, Guilherme Gomidec, Jerome Depeyrot \\ ${ }^{a}$ Universidade de Brasília, Faculdade UnB Planaltina, Laboratório de Nanociência Ambiental, \\ 73345-010, Brasília, DF, Brasil. \\ ${ }^{b}$ Universidade de Brasília, Instituto de química, 70910-900, Brasília, DF, Brasil. \\ ${ }^{c}$ Universidade de Brasília, Instituto de física, Grupo de Fluidos Complexos, 70919-970, Brasília, DF, \\ Brasil.
}

Received: May 06, 2021; Revised: Jul 07, 2021; Accepted: Aug 01, 2021

\begin{abstract}
Magnetic nanopowders were developed by functionalization of bimagnetic core@shell nanoparticles with cysteine $\left(\mathrm{CoFe}_{2} \mathrm{O}_{4} @ \mathrm{\gamma}-\mathrm{Fe}_{2} \mathrm{O}_{3} @ \mathrm{Cys}\right)$, which present a core with high saturation magnetization $\left(\mathrm{CoFe}_{2} \mathrm{O}_{4}\right)$ combined with a shell with high long-term chemical stability $\left(\mathrm{\gamma}-\mathrm{Fe}_{2} \mathrm{O}_{3}\right)$ and a sorptive L-cysteine layer. Samples of two different mean sizes were elaborated and characterized by XRD, TEM, FTIR, SER, zetametry and SQUID magnetometry. The adsorption of $\mathrm{Pb}$ (II) by the magnetic nanopowders was investigated as a function of $\mathrm{pH}$, time, and pollutant concentration. The Langmuir model fitted well the adsorption data indicating monolayer adsorption, and a maximum adsorption capacity of $1.2 \mathrm{mg} / \mathrm{g}$ was found for $\mathrm{pH}$. The kinetic data were well correlated to the pseudo-secondorder model and the best equilibrium time was $120 \mathrm{~min}$. The adsorption mechanism mainly involves electrostatic interactions in $\mathrm{pH} \mathrm{5-7}$ and hard-soft-acid-base interactions in low $\mathrm{pH}$. Moreover, the nanoparticles were recovered and reused in readsorption experiments keeping a good removal efficiency.
\end{abstract}

Keywords: nanopowders; magnetic nanocomposite; magnetic separation; pollutant removal.

\section{Introduction}

Due to the great importance of potable water for the maintenance of life and its gradually scarce availability, the spread of contaminants in water bodies has become an increasingly serious problem. In urban centers, water contamination by non-biodegradable and toxic wastes occurs both by human activity as well as industrial effluents that are discharged into water bodies, thus altering the balance of ecosystems and causing a worsening of the quality of life ${ }^{1,2}$. At the global level, a class of pollutants that require more care are the potentially toxic metals, such as arsenic (As), cadmium $(\mathrm{Cd})$, and lead $(\mathrm{Pb})^{3}$ which, even at low concentrations, represent a serious threat to plants, animals, and humans due to their high toxicity, and bioaccumulative and non-biodegradable properties ${ }^{4,5}$.

Among the potentially toxic metals, lead is one of those with the highest risks to human health, since it accumulates in the body and has no physiological function ${ }^{6}$. Contamination by this metal can cause serious damage to the liver and kidneys, dysfunction in the formation of hemoglobin, mental retardation, infertility, and fetal abnormalities ${ }^{7}$. The World Health Organization (WHO) has set the maximum allowable $\mathrm{Pb}$ concentration of $10 \mu \mathrm{g} / \mathrm{L}$ in drinking water ${ }^{8}$. It has been used in the manufacture of batteries and ammunition for

*e-mail: relex@unb.br weapons, in glass and ceramic printing factories and the production line of metallurgical industries ${ }^{9}$.

Currently, the search for methods to remove $\mathrm{Pb}$ from water has been increasing. Some usual technologies are based on chemical precipitation ${ }^{10}$, ionic exchange ${ }^{11,12}$, membrane filtration $^{13}$, electrolytic methods ${ }^{14}$, reverse osmosis ${ }^{15}$, and solvent extraction ${ }^{16}$. However, most of these methods have disadvantages due to limitations in the $\mathrm{pH}$ range since they use the reduction of metal ions as the main mechanism of action $^{17}$, as well as the high cost, difficulty of operation and significant energy consumption ${ }^{18}$. In this scenario, one of the most effective techniques for treating water containing toxic metals is the adsorption, which besides offering flexibility in design and operation, allows the regeneration of the adsorbent by desorption process and can also produce high quality treated effluent ${ }^{19}$. Biomass, moss, ash, clays, activated carbon and zeolites are adsorbents commonly used due to their low-cost ${ }^{7}$. Beside this, to increase the efficiency of the adsorption process, nanoscale adsorbents (called nanosorbents) are used due to the large surface area per unit of mass and the high reactivity on the surface per volume unit $^{20}$. However, the small size of the nanosorbents makes it difficult to separate them from the effluent, after the adsorption process. To avoid this problem, magnetic nanoadsorbents have been increasingly used since they can be easily removed by an external magnetic field, allowing the treatment of a 
large amount of water and not generating other residues in this process ${ }^{21}$. Recent research indicates that the surface of magnetic nanoparticles (NPs) can be coated with different binders, increasing the adsorption capacity depending on the target pollutant $t^{9,22,23}$. For $\mathrm{Pb}$, functionalization with amino acids is efficient because it contains the carboxyl group that can complex with this metal and the amino group that works as a chelator ${ }^{24,25}$. Among the amino acids, L-cysteine is a very promising choice because it contains sulfur, which has a strong tendency to coordinate with lead cation forms ${ }^{26}$.

Nanoadsorbents based on magnetite $\left(\mathrm{Fe}_{3} \mathrm{O}_{4}\right)$ have been widely used for the removal of contaminants in aqueous media, as they present high saturation magnetization, nontoxicity, hydrophilicity, and low production cost. However, synthetic magnetite nanoparticles undergo oxidation in the presence of oxygen, resulting in a reduction in the adsorbent lifetime and the efficiency in material separation since there is a decrease in its saturation magnetization ${ }^{27}$. The application of nanoadsorbents based on other types of ferrites $\left(\mathrm{MFe}_{2} \mathrm{O}_{4} ; \mathrm{M}=\mathrm{Mn}, \mathrm{Co}, \mathrm{Ni}, \mathrm{Cu}\right.$ and $\left.\mathrm{Zn}\right)$ has also been studied to remove several different pollutant classes from water ${ }^{28}$. However, when applied in low $\mathrm{pH}$ range, these materials suffer dissolution, which reduces their lifetime. A viable solution is to cover the nanoadsorbent surface with maghemite $\left(\mathrm{\gamma}-\mathrm{Fe}_{2} \mathrm{O}_{3}\right)$, which despite having less saturation magnetization (when on a nanometer scale), has a high adsorption capacity and provides chemical stability to the particle preventing its dissolution or oxidation ${ }^{29}$.

In this context, the main goal of this survey is to investigate the applicability of magnetic nanopowders based on hybrid nanomaterials for the removal of lead $\left(\mathrm{Pb}^{2+}\right)$ from water. The nanomaterials are composed of magnetic core@shell nanoparticles coated by a superficial layer of L-cysteine $\left(\mathrm{CoFe}_{2} \mathrm{O}_{4} @ \mathrm{\gamma}_{\mathrm{\gamma}}-\mathrm{Fe}_{2} \mathrm{O}_{3} @ \mathrm{Cys}\right)$. The magnetic part of the nanomaterial provides a core with high saturation magnetization $\left(\mathrm{CoFe}_{2} \mathrm{O}_{4}\right)$ combined with a shell with high long-term chemical stability $\left(\mathrm{\gamma}-\mathrm{Fe}_{2} \mathrm{O}_{3}\right)$. The L-cysteine layer offers a sorptive surface due to the presence of the carboxylate, amino and thiol groups that present good interaction with the $\mathrm{Pb}^{2+}$ ions. Samples of nanoparticles with two mean sizes were prepared and characterized structurally, morphologically, and magnetically to confirm their structure and response to an external magnetic field. The absorption capacity of the nanopowders was investigated through batch studies checking the influence of $\mathrm{pH}$, contact time and initial concentration of $\mathrm{Pb}$ (II). The possible mechanisms of $\mathrm{Pb}$ (II) adsorption were proposed. Finally, the regeneration capacity and reusability of the magnetic powders were studied.

\section{Materials and Methods}

\subsection{Reagents and equipment}

All chemicals used in this work were either analytical or guaranteed reagent grade (Sigma-Aldrich or Merck) and were used without further purification. Standard solutions of $\mathrm{Pb}(\mathrm{II})$ were prepared in deionized water Type I (Millipore Milli-Q Gradient quality) from a commercial standard stock solution at $1000 \mathrm{mg} / \mathrm{L}$ (Merck). Solutions of $\mathrm{HNO}_{3}(0.1 \mathrm{~mol} / \mathrm{L})$ and $\mathrm{NaOH}(0.1 \mathrm{~mol} / \mathrm{L})$ were used in $\mathrm{pH}$ adjustments. Solution $\mathrm{pH}$ were measured using a $\mathrm{pH}$-meter
(Metrohm, model 713) with a pH glass double-junction electrode. The adsorption experiments were carried out using an orbital shaker (Gehaka, model AO-370) at a constant speed and temperature. The equilibrium concentrations of $\mathrm{Pb}$ (II) were determined by flame atomic absorption spectroscopy (FAAS) at $270 \mathrm{~nm}$ wavelength (Thermo Scientific, S Series spectrometer) with external calibration. The correlation coefficient of the calibration curve was 0.999 and the figures of merit for the instrument, such as limit of detection, limit of quantification, linear dynamic range and calibration sensitivity were $0.054 \mathrm{mg} / \mathrm{L}, 0.180 \mathrm{mg} / \mathrm{L}, 0.054-20 \mathrm{mg} / \mathrm{L}$ and $0.014 \mathrm{~L} / \mathrm{mg}$, respectively. All the measurements were carried out in triplicate.

\subsection{Sample synthesis}

The magnetic nanopowders were synthesized in two main stages, namely elaboration of the precursor nanoparticles followed by their functionalization with L-cysteine. In the first stage, the precursor magnetic nanoparticles were synthesized by following the well-known procedures described elsewhere ${ }^{30,31}$. First, $\mathrm{CoFe}_{2} \mathrm{O}_{4}$ nanoparticles were elaborated through a hydrothermal coprecipitation of aqueous $0.5 \mathrm{~mol} / \mathrm{L}$ $\mathrm{Co}\left(\mathrm{NO}_{3}\right)_{2} \cdot 6 \mathrm{H}_{2} \mathrm{O}$ and $0.5 \mathrm{~mol} / \mathrm{L} \mathrm{FeCl} \cdot 9 \mathrm{H}_{2} \mathrm{O}$ solutions in alkaline medium. In this step, the nanoparticles diameter can be roughly tuned by controlling the hydroxide concentration in synthesis medium ${ }^{32}$. In the present study, sodium hydroxide $(\mathrm{NaOH})$ and methylamine $\left(\mathrm{CH}_{3} \mathrm{NH}_{2}\right)$ were used to elaborate $\mathrm{CoFe}_{2} \mathrm{O}_{4}$ nanoparticles samples of larger and smaller mean sizes, respectively. Afterward, the nanoparticles of each sample were washed with distilled water several times and hydrothermally treated with a $0.5 \mathrm{~mol} / \mathrm{L} \mathrm{Fe}\left(\mathrm{NO}_{3}\right)_{3}$ solution for $15 \mathrm{~min}$. As a result, the nanocrystals had their surface covered with a thin layer of maghemite $\left(\mathrm{\gamma}-\mathrm{Fe}_{2} \mathrm{O}_{3}\right)$ leading to the two precursor core@shell nanoparticles samples $\left(\mathrm{CoFe}_{2} \mathrm{O}_{4} @ \mathrm{\gamma}-\mathrm{Fe}_{2} \mathrm{O}_{3}\right)$ labelled as \#u-Cys-S (smaller size) and \#u-Cys-L (larger size). This shell endows the nanoparticles with long-term stability preventing their dissolution in acidic medium. The structure of these core@shell-type nanoparticles has been extensively studied elsewhere ${ }^{33-36}$.

In the second stage, the functionalization of the nanoparticles with L-cysteine was carried out following the procedure proposed by Gawande et $\mathrm{al}^{7}$. Briefly, $1 \mathrm{mg}$ of each sample of precursor nanoparticles (\#u-Cys-S and \#u-Cys-L) was dispersed in $20 \mathrm{~mL}$ type I water and mixed with $40 \mathrm{~mL}$ methanol-water (1:1) solution containing $1 \mathrm{~g}$ of L-cysteine hydrochloride monohydrate at room temperature. The system was stirred for $24 \mathrm{~h}$ at $1200 \mathrm{rpm}$ using a magnetic stirrer device. Then, the nanopowder samples with the surface coated nanoparticles $\left(\mathrm{CoFe}_{2} \mathrm{O}_{4} @ \mathrm{\gamma}-\mathrm{Fe}_{2} \mathrm{O}_{3} @ \mathrm{Cys}\right)$ were separated from the medium by magnetic decantation and successively washed with water and methanol, and finally dried under vacuum for $2 \mathrm{~h}$ at $60{ }^{\circ} \mathrm{C}$. The magnetic nanopowder samples composed of nanoparticles with larger and smaller mean sizes were labeled as \#Cys-L and \#Cys-S, respectively.

\subsection{Characterization of the nanopowders}

$\mathrm{X}$-ray diffraction (XRD) experiments were carried out in a Bruker D8 Focus using Cu-K $\alpha$ radiation $(\lambda=0.15406 \mathrm{~nm})$ in a range of $2 \theta$ from $20^{\circ}$ to $80^{\circ}$ with a step of $0.05^{\circ}$. Experimental results are compared with data from the International 
Centre for Diffraction Data (ICDD). Transmission Electron Microscopy (TEM) and High-Resolution Transmission Electron Microscopy (HRTEM) were performed using a JEOL JEM2100 electron microscope. The size distribution was obtained by measuring the diameter of the NPs in the TEM micrographs, and it was well adjusted with a lognormal probability distribution function

$P(D)=\frac{1}{x \sigma \sqrt{2 \pi}} e^{-\frac{\ln ^{2}\left(d / d_{0}\right)}{2 \sigma^{2}}}$,

where $\sigma$ is the polydispersity index and $\mathrm{d}_{0}$ the median diameter of the distribution.

Fourier transform infrared spectroscopy (FTIR) and surface-enhanced Raman spectroscopy (SER) were performed to gain further surface structural insights about the prepared nanopowders. FTIR spectra (Perkin Elmer spectrophotometer, model Frontier) were registered from 4000 to $400 \mathrm{~cm}^{-1}$ (transmittance mode) using 8 scans at $4 \mathrm{~cm}^{-1}$ resolution. Before the measurements, the nanopowder samples were mixed with potassium bromide and pressed at 10 tons on a hydraulic press (Pike Technologies, model Auto-CrushIR) to obtain samples of pellets of $\mathrm{KBr}$. SER experiments were carried out (Jobin-Yvon triple spectrometer, model T64000 model) with spectral resolution of $4 \mathrm{~cm}^{-1}$ (1,800 grooves $\mathrm{mm}^{-1}$ grating). The samples were optically excited using the $532 \mathrm{~nm}$ line of an argon ion laser. The signal was collected in backscattering configuration using a spherical lens $(\mathrm{NA}=0.55)$, while a $\mathrm{CCD}$ camera was used to record the SER spectra.

The magnetic properties were investigated in pressed powder samples using a commercial Quantum Design Superconducting Quantum Interference Device (SQUID) magnetometer (model MPMS3) with a maximum field of $7 \mathrm{~T}$.

The type of surface charge (positive or negative) of the nanoparticles as a function of $\mathrm{pH}$ was evaluated using the electrophoretic light scattering measurements (ELS). Before the analysis, the dispersions of the nanopowders $(10 \mathrm{mg} / \mathrm{L}$ in $0.01 \mathrm{~mol} / \mathrm{L} \mathrm{NaNO}_{3}$ ) were sonicated for $15 \mathrm{~min}$ with an ultrasonic disperser (Gehaka, model DU-15). The experiments were performed using a ZetaSizer (Malvern, model NanoZS 90) and the obtained electrophoretic mobilities were converted to zeta potentials using the Henry equation ${ }^{38}$.

\subsection{Batch adsorption studies}

The batch adsorption experiments were carried out on the orbital shaker mixing $20 \mathrm{mg}$ of each magnetic nanopowder sample with $15 \mathrm{~mL}(1.33 \mathrm{~g} / \mathrm{L})$ of $\mathrm{Pb}(\mathrm{II})$ solutions of varying concentrations (1-30 mg/L) under previously determined standard conditions ( $\mathrm{pH} 5$, shaking rate of $400 \mathrm{RPM}$, contact time of 240 minutes and at $25^{\circ} \mathrm{C}$ ) unless otherwise specified. After reaching the equilibrium, the magnetic nanopowder loaded with lead was separated from the medium using a hand-held permanent magnet (Nd-Fe-B) for 15 minutes and the concentration of $\mathrm{Pb}$ (II) in the supernatant was determined. The adsorption experiments were repeated with $2.5 \mathrm{mg} / \mathrm{L}$ $\mathrm{Pb}$ (II) solutions at different $\mathrm{pH}$ values $(3.0 ; 4.0 ; 4.5 ; 5.0 ; 5.5)$ to characterize the $\mathrm{pH}$-dependence of the adsorption process. The kinetics of adsorption was evaluated from experiments changing the contact time between the pollutant and the nanoadsorbent from 0 to 360 minutes in the adsorption tests for $2.5 \mathrm{mg} / \mathrm{L} \mathrm{Pb}$ (II) solutions at $\mathrm{pH} 5$.

\subsection{Regeneration experiments}

The reusability of the nanoadsorbents was investigated by desorption and readsorption experiments. The desorption experiment was performed washing the lead-loaded nanopowders with $0.01 \mathrm{~mol} / \mathrm{L} \mathrm{NaOH}$ aqueous solution for $30 \mathrm{~min}$. Afterward, the regenerated nanopowder was magnetically separated and dried in an oven at $60{ }^{\circ} \mathrm{C}$. Then, the nanopowder was tested for readsorption under the previously described standard conditions.

\subsection{Equilibrium and Kinetic Modeling}

The amount of $\mathrm{Pb}$ (II) adsorbed onto the nanoparticles at equilibrium $\left(q_{\mathrm{e}}, \mathrm{mg} / \mathrm{g}\right)$ and the removal efficiency (Removal $(\%)$ ) from the aqueous solution were calculated according to the following equations:

$q_{e}=\frac{\left(C_{0}-C_{e}\right)}{m} V$,

$\operatorname{Removal}(\%)=\frac{\left(C_{0}-C_{e}\right)}{C_{0}} \times 100$,

where $C_{0}$ and $C_{\mathrm{e}}$ are the initial and equilibrium $\mathrm{Pb}(\mathrm{II})$ concentrations $(\mathrm{mg} / \mathrm{L})$ in solution, respectively, $V(\mathrm{~L})$ is the volume of the solution and $m(\mathrm{~g})$ is the weight of the nanoparticle.

The adsorption isotherm data were fitted to the following linearized form of Langmuir model ${ }^{39}$ :

$$
\frac{C_{e}}{q_{e}}=\frac{1}{K_{L} q_{\max }}+\frac{C_{e}}{q_{\max }},
$$

where $q_{\max }(\mathrm{mg} / \mathrm{g})$ is the maximum adsorption capacity, $K_{L}$ $(\mathrm{L} / \mathrm{mg})$ is the Langmuir adsorption constant, which is related to the adsorption affinity ${ }^{40}$. The favorability of the adsorption process was estimated by a dimensionless separation factor $\left(R_{L}\right)$, calculated as:

$$
R_{L}=\frac{1}{1+C_{0} K_{L}} .
$$

The kinetics of $\mathrm{Pb}(\mathrm{II})$ adsorption was investigated with the pseudo-first-order (PFO) and the pseudo-secondorder (PSO) models, according to the following equations, respectively ${ }^{41-43}$ :

$$
\begin{aligned}
& q_{t}=q_{e}\left(1-e^{-k_{1} t}\right), \\
& q_{t}=\frac{q_{e}^{2} k_{2} t}{1+q_{e} k_{2} t},
\end{aligned}
$$

where $q_{t}(\mathrm{mg} / \mathrm{L})$ is the amount of $\mathrm{Pb}$ (II) adsorbed at time $t$ (min), $k_{1}\left(\mathrm{~min}^{-1}\right)$ and $k_{2}(\mathrm{~g} / \mathrm{min} \mathrm{mg})$ are the pseudo first- and pseudo second-order rate constants, respectively.

The quality of the fitting results was evaluated using the mean absolute percentage error (MAPE):

$$
\operatorname{MAPE}(\%)=\frac{\sum_{i=1}^{N}\left|\frac{q_{\exp }-q_{\text {calc }}}{q_{\exp }}\right|}{N} \times 100,
$$


where $N$ is the number of replicates, and $q_{\text {exp }}(\mathrm{mg} / \mathrm{g})$ and $q_{\text {calc }}(\mathrm{mg} / \mathrm{g})$ are the experimental and predicted adsorption capacities, respectively.

\section{Results and Discussion}

\subsection{Characterization of the nanopowders}

The precursor nanoparticles and the nanoadsorbents underwent structural and morphological characterization by XRD, TEM and HRTEM, all shown in Figure 1. The X-ray diffractograms are depicted in panels a) and b), respectively, for the precursor NPs and the nanoadsorbents. For the precursor nanoparticles, we observe the characteristic (labeled) reflections of the spinel structure. They are well adjusted by simultaneous fitting with a pseudo-Voigt function for each of the seven most intense peaks. The lattice parameters, which are collected in Table 1, are consistent with previous reports ${ }^{33,44,45}$ and agree well with the expected for core@shell nanoparticles with a cobalt ferrite core and a maghemite shell, with cell sizes lying between that of $\mathrm{CoFe}_{2} \mathrm{O}_{4}$ (ICDD 00-022-1086) and $\gamma-\mathrm{Fe}_{2} \mathrm{O}_{3}$ (ICDD 98-008-7119). On panel b) are depicted the diffractograms for the nanoadsorbents, i.e., after the functionalization with L-Cysteine. The reflections from the spinel structure are present, along with other peaks, including one much more intense than the most intense among the spinel ones (311). These reflections that are present on the nanoadsorbents are probable related to the functionalized species. For comparison, colored lines are shown at the bottom. The peaks in green indicate the presence of cystine ${ }^{46}$, an oxidized dimer form of cysteine, while the reflections in purple and orange are either present in both cystine and cysteine or just in cysteine. The reflections seem to indicate the presence of both cysteine and cystine in the nanoadsorbents. The formation of cystine will be explored in detail later from the FTIR and SER results.

Besides the determination of the structural parameters of the precursor NPs and the nanoadsorbents, XRD was also used to determine the average crystallite size using Scherrer's equation applied to seven of the most intense peaks for the precursor nanoparticles and four of those for the nanoadsorbents, due to the removal of peaks that overlapped with those coming from cysteine or cystine. The results, collected in Table 1, show two different sizes between the -S and -L samples, with no significant differences between the nanoadsorbents their precursor NPs counterpart, as expected.

Transmission Electron Microscopy was used as an additional technique to characterize the size distribution of the samples. Diameter distribution histograms are collected in Figure $1 \mathrm{c}, \mathrm{d}$. In contrast to $D_{R X}$ values, there is a slight difference between the nanoadsorbents and the precursor nanoparticles in what concerns the median diameter, which is likely related to the sampling, since particle viewed by TEM represent a minor fraction of the ones observed by XRD. The HRTEM micrographs, shown in panels $1 \mathrm{e}-\mathrm{h}$ )
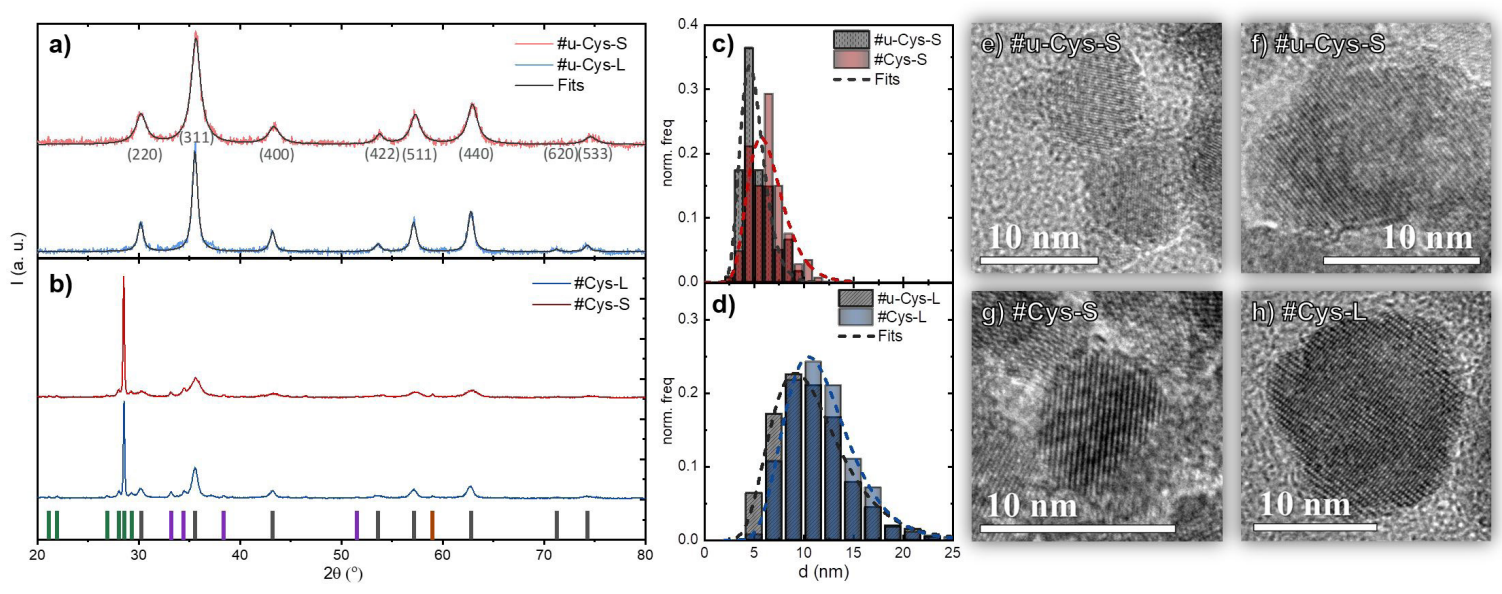

Figure 1. a) Experimental X-ray diffractograms of the uncoated NPs along with the simultaneous fitting of the detectable peaks for diameter and structural parameters determination. Spinel peaks are indexed for clarity. b) X-ray diffractograms of \#Cys-L and \#Cys-S samples. The short lines at the bottom indicate the peak positions of cysteine (orange), cystine (green), and $\mathrm{CoFe}_{2} \mathrm{O}_{4}$ (dark grey). The positions marked in purple have reflections coming from both cystine and cysteine. c) and d) show the diameter distribution histogram obtained by TEM along with their best fits using the lognormal distribution. e), f), g) and h) show typical HRTEM micrographs of each of the samples.

Table 1. Structural, morphological, and magnetic parameters of the precursor nanoparticles and nanoadsorbents. $D_{R X}$ is the diameter obtained by using Scherrer's equation, $<a>$ is the mean lattice parameter of the spinel structure, $d_{0}$ is the median diameter of the lognormal distribution of diameters and $\sigma$ the polydispersity index. $M_{S}$ is the saturation magnetization and $\chi_{0}$ the low field initial magnetic susceptibility.

\begin{tabular}{ccccccc}
\hline Sample & $D_{R X}(\mathrm{~nm})$ & $<a>(\AA)$ & $d_{0}(\mathrm{~nm})$ & $\sigma$ & $M_{S}(\mathrm{emu} / \mathrm{g})$ & $\chi_{0}$ \\
\hline \#u-Cys-L & $13.8 \pm 0.7$ & $8.367 \pm 0.004$ & $10.4 \pm 0.1$ & 0.35 & $63.5 \pm 0.1$ & 1.84 \\
\hline \#u-Cys-S & $7.2 \pm 0.6$ & $8.346 \pm 0.006$ & $4.8 \pm 0.2$ & 0.25 & $53.6 \pm 0.1$ & 2.76 \\
\hline \#Cys-L & $13.0 \pm 0.9$ & $8.374 \pm 0.004$ & $11.4 \pm 0.1$ & 0.30 & $40.4 \pm 0.1$ & 1.64 \\
\hline \#Cys-S & $7.6 \pm 0.7$ & $8.347 \pm 0.005$ & $6.2 \pm 0.3$ & 0.30 & $31.2 \pm 0.1$ & 2.06 \\
\hline
\end{tabular}


for typical NPs, illustrate the nearly-spherical morphology of the particles and their crystallinity.

To assess the magnetic properties of the nanoadsorbents, room temperature magnetization curves as a function of applied field were carried out. Results are depicted in Figure 2 for both the precursor NPs and the nanoadsorbents and show a superparamagnetic-like behavior in all cases, with magnetization increasing as applied field continuously increases until saturation magnetization $\left(M_{S}\right)$ is achieved. The inset shows a magnification of the low field area, highlighting the linear behavior that allows us to obtain the initial magnetic susceptibility $\chi_{0}$. Values of both quantities are collected in Table 1. By comparing the $M_{S}$ values between the -L samples and their -S counterparts, we verify that the samples with greater diameter have a greater $M_{S}$, as expected. An inverse trend is observed for the initial susceptibility, where the larger NPs have lower $\chi_{0}$ values. This was also observed in a previous work and has been attributed to the more significant presence of blocked NPs in the samples with greater diameter ${ }^{44}$.

By analyzing the change in magnetization between the precursor nanoparticles and the respective nanoadsorbent, we can get some valuable insight on the functionalization process. In this case, the reduction in saturation magnetization is related to the increase in mass of non-magnetic material due to the surface functionalization. Based on the obtained $M_{S}$ values, sample \#Cys-L suffers a reduction of approximately $37 \%$ in magnetization, while for \#Cys-S, the magnetization reduces by $42 \%$. The fact that reduction is greater for the smaller nanoadsorbents directly reflects the higher surface/volume ratio observed in smaller NPs.

The same procedure can be carried out for the magnetic susceptibility, and, if the changes in $\chi_{0}$ are just due to the changes in $M_{S}$, then we should observe the same reduction as before. The results show that the $\chi_{0}$ reduction is much less significant (10\% and $25 \%$ for - $\mathrm{L}$ and -S samples, respectively). Besides enabling a better magnetic separation, these higher values of magnetic susceptibility suggest a lesser influence of dipolar interactions ${ }^{47}$, probably due to the additional surface barrier created from the functionalization process.

Figure 3 exhibits the FTIR spectra of the pure commercial L-cysteine hydrochloride monohydrate and nanopowder samples. The main peaks associated to $\mathrm{CoFe}_{2} \mathrm{O}_{4} @ \gamma-\mathrm{Fe}_{2} \mathrm{O}_{3} @$ Cys can be observed, confirming the functionalization. In the spectrum of pure L-cysteine hydrochloride monohydrate, the large broad band between 3000 and $3500 \mathrm{~cm}^{-1}$ (A) mainly corresponds to the asymmetric $\mathrm{NH}_{3}^{+}$stretching and the weak signal at around $2560 \mathrm{~cm}^{-1}$ (B) belongs to $\mathrm{S}-\mathrm{H}$ stretching vibration. The typical sharp bands at 1740 and $1514 \mathrm{~cm}^{-1}(\mathrm{C})$ are due to the asymmetric and symmetric $\mathrm{C}=\mathrm{O}$ stretching modes of the $\mathrm{COOH}$ group, while the less intense peaks at 1626 and $1568 \mathrm{~cm}^{-1}$ (C) correspond to the asymmetric and symmetric bending of $\mathrm{NH}_{3}^{+48}$. In the FTIR spectra of the nanopowders, the sharp band at $605 \mathrm{~cm}^{-1}$ (F) belongs to the characteristic $\mathrm{Fe}-\mathrm{O}$ vibration in the tetrahedral sites of the spinel structure $^{49}$. The absence of the peak related to the $\mathrm{S}-\mathrm{H}$ group indicates that the cysteine molecules attach the surface of the nanoparticles via the formation of Fe-S bonding ${ }^{50,51}$. Another interesting binding behavior of cysteine on the nanoparticle surface deduced from the spectra is the formation of cystine, as already observed in similar nanomaterials $\mathrm{s}^{52,53}$ and indicated by the XRD results. Indeed, the bands at 2581 (D), 847 (E), $676(\mathrm{~F})$ and $540 \mathrm{~cm}^{-1}(\mathrm{H})$ are characteristic of symmetric $\mathrm{NH}_{3}^{+}$stretching, $\mathrm{NH}_{3}^{+}$rocking, $\mathrm{C}-\mathrm{S}$ and $\mathrm{S}-\mathrm{S}$ stretching of cystine, respectively $\mathrm{y}^{54-56}$. The formation of cystine is further demonstrated by SER measurements (Figure 4), where the strong characteristic $\mathrm{S}-\mathrm{S}$ vibration at $500 \mathrm{~cm}^{-1}$ is observed $\mathrm{d}^{57,58}$. The spectra also show the bands corresponding to $\mathrm{Fe}-\mathrm{O}$ and $\mathrm{C}-\mathrm{S}$ vibrations. According to the literature, the mechanism of cystine formation involves the reduction of $\mathrm{Fe}^{3+}$ ions on the nanoparticle surface and the corresponding oxidation of two adsorbed cysteine molecules leading to the $\mathrm{S}-\mathrm{S}$ bond formation ${ }^{52}$. In the FTIR spectra of the nanopowder samples, the sharp shift of the asymmetric and symmetric stretching of $\mathrm{COO}^{-}$to 1585 and $1402 \mathrm{~cm}^{-1}$ respectively, compared to the pure L-cysteine, indicates that the cystine is bonded to the nanoparticle surface via carboxylate group ${ }^{59}$. Moreover, the splitting of the $\mathrm{COO}^{-}$stretching wavenumbers suggests that the coordination between the carboxylate and the surface cations are mostly bridged (binuclear bidentate) or ionic ${ }^{59-62}$.

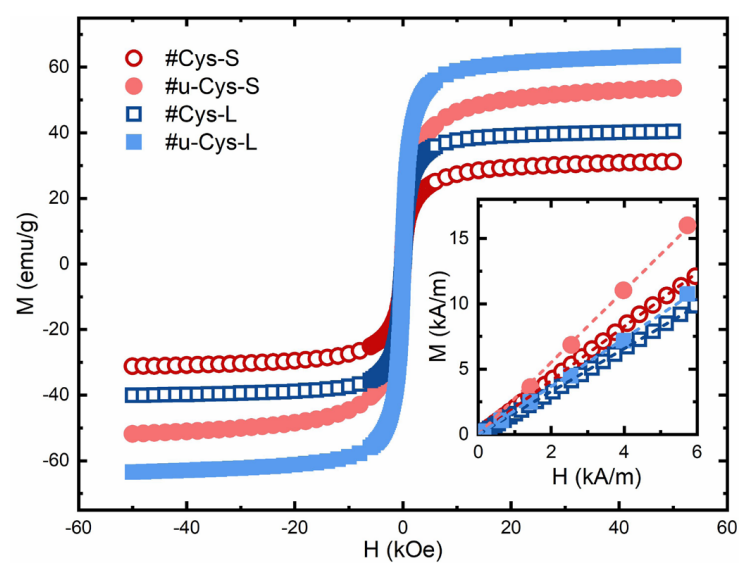

Figure 2. Room temperature magnetization curves of studied samples. Inset shows a magnification of the low field are, enhancing the visualization of the low field magnetic susceptibilities.

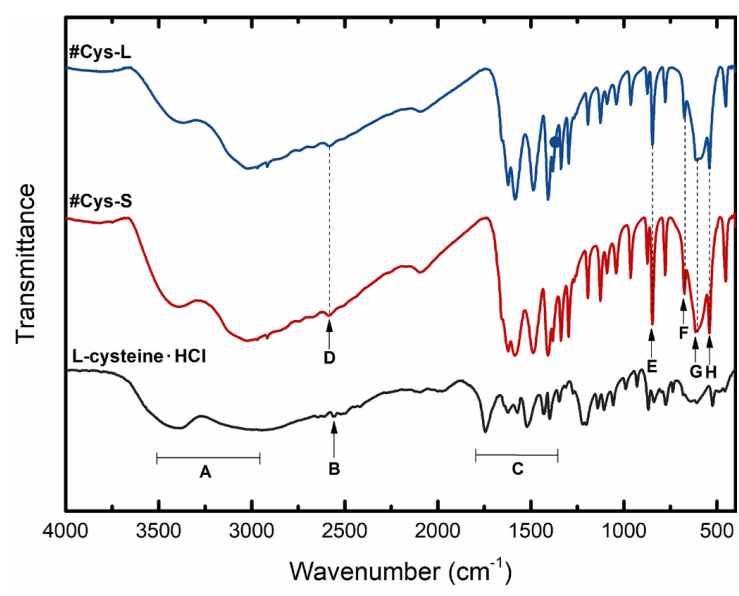

Figure 3. FTIR spectra of the pure commercial L-cysteine hydrochloride monohydrate and nanopowder samples. 
The profile of the zeta potential of the $\mathrm{CoFe}_{2} \mathrm{O}_{4} @ \mathrm{\gamma}-$ $\mathrm{Fe}_{2} \mathrm{O}_{3} @$ Cys nanoparticles in the pH range of 3-6 is shown in Figure 5, where an isoelectric point (IEP) at around 3.7 was found for both nanopowder samples. The type of surface charge results from the overall balance of protonation of amino groups and deprotonation of carboxyl groups on the nanoparticle surface. Bellow IEP, the protonation of amino groups of cysteine and cystine leads to a net positive charge while above IEP the deprotonation of carboxyl groups of cysteine renders the overall charge negative.

\subsection{Effect of $p H$ and Mechanism Studies}

The effect of $\mathrm{pH}$ on $\mathrm{Pb}(\mathrm{II})$ adsorption by the $\mathrm{CoFe}_{2} \mathrm{O}_{4} @ \mathrm{\gamma}-$ $\mathrm{Fe}_{2} \mathrm{O}_{3} @$ Cys nanoparticles is shown in Figure 6 and provides important information concerning the adsorption mechanism. As it can be seen, the percentage of removal increases with increasing $\mathrm{pH}$ in the investigated range, where the optimal value was obtained at $\mathrm{pH}$ 5-6. This result can be enlightened considering the interplay between the surface charge of the nanoparticles, the type of surface groups and the $\mathrm{Pb}$ (II) speciation in aqueous solution. Depending on the $\mathrm{pH}$ of the medium, $\mathrm{Pb}(\mathrm{II})$ can be found in different forms, such as $\mathrm{Pb}^{2+}$, $\mathrm{Pb}(\mathrm{OH})^{+}, \mathrm{Pb}(\mathrm{OH})_{2}, \mathrm{~Pb}(\mathrm{OH})_{3}{ }^{-}$and $\mathrm{Pb}_{3}(\mathrm{OH})_{4}{ }^{2+63}$. At $\mathrm{pH} \leq 5.0$, $\mathrm{Pb}$ (II) is found exclusively in the $\mathrm{Pb}^{2+}$ form while at $\mathrm{pH}$ between 5 and 7 , both $\mathrm{Pb}^{2+}$ and $\mathrm{Pb}(\mathrm{OH})^{+}$species coexist. For $\mathrm{pH}>7.0, \mathrm{~Pb}$ (II) tends to precipitate as $\mathrm{Pb}(\mathrm{OH})_{2}$, where the excess of hydroxide ions in strong alkaline medium $\left(\mathrm{pH} \geq 12\right.$ ) leads to $\mathrm{Pb}(\mathrm{OH})_{3}{ }^{-}$as the predominant form.

The greater removal capacity at higher $\mathrm{pH}$ values in the investigated range can be correlated to the increasing of the negative surface charge of the nanoparticles (more negative zeta potential) leading to a very favorable adsorption of the cationic forms of $\mathrm{Pb}(\mathrm{II})$. With decreasing $\mathrm{pH}$, the charge of the nanoparticles become less negative reducing the electrostatic attraction and then the removal efficiency. At $\mathrm{pH}$ 3, the overall charge of the nanoparticles is positive, and the lead removal reaches its lowest percentage mainly because of the electrostatic repulsion between the positive surface charge and the $\mathrm{Pb}^{2+}$ ions. At this $\mathrm{pH}$ region, the lead adsorption may occur toward the thioether group of cystine based on Pearson's Hard Soft Acid Base Theory, where the $\mathrm{Pb}^{2+}$ ions and the sulfur of thioether groups behave as an acid and a base, respectively. This hypothesis is consistent with the shift of the S-S stretching band to lower wavenumbers in the FTIR spectra of the nanopowders after lead adsorption at $\mathrm{pH} 3$ (Figure 7).

Based on the possible adsorption mechanisms, the proposed magnetic nanopowders may be applied to remove other toxic metals that form cationic species at $\mathrm{pH}$ between 5 and 7 , such as cadmium $\left(\mathrm{Cd}^{2+}\right.$ and $\left.\mathrm{CdOH}^{+}\right)$, copper $\left(\mathrm{Cu}^{2+}\right.$ and $\left.\mathrm{CuOH}^{+}\right)$, and zinc $\left(\mathrm{Zn}^{2+}\right.$ and $\left.\mathrm{ZnOH}^{+}\right)$or that form complexes with thioether, such as mercury $\left(\mathrm{Hg}^{2+}\right)$.

\subsection{Adsorption kinetics}

The effect of contact time on $\mathrm{Pb}$ (II) adsorption by the $\mathrm{CoFe}_{2} \mathrm{O}_{4} @ \mathrm{\gamma}-\mathrm{Fe}_{2} \mathrm{O}_{3} @$ Cys nanoparticles is exhibited in Figure 8 . As it can be seen, the removal of $\mathrm{Pb}$ (II) was fast in the first one hour and then progressively slowed down until the equilibrium time of $120 \mathrm{~min}$ for sample \#Cys-L and 240 min for sample \#Cys-S. The calculative results from

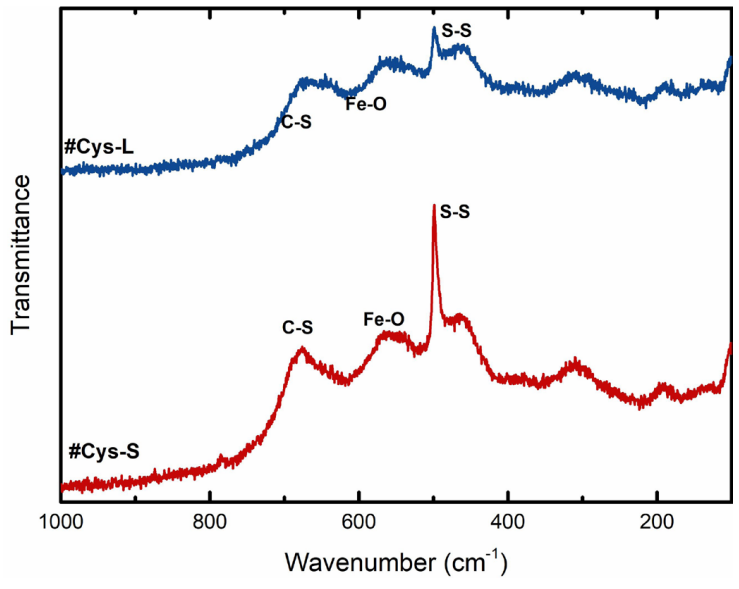

Figure 4. SER spectra of the nanopowder samples. The strong characteristic $\mathrm{S}-\mathrm{S}$ vibration at $500 \mathrm{~cm}^{-1}$ confirms the formation of cystine in the coating process.

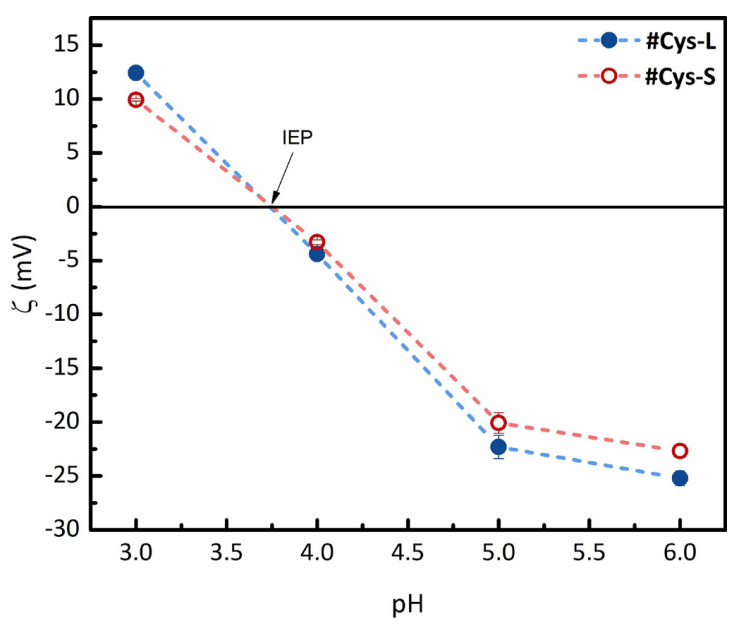

Figure 5. Zeta potential of the $\mathrm{CoFe}_{2} \mathrm{O}_{4} @ \gamma-\mathrm{Fe}_{2} \mathrm{O}_{3} @$ Cys nanoparticles as function of $\mathrm{pH}$.

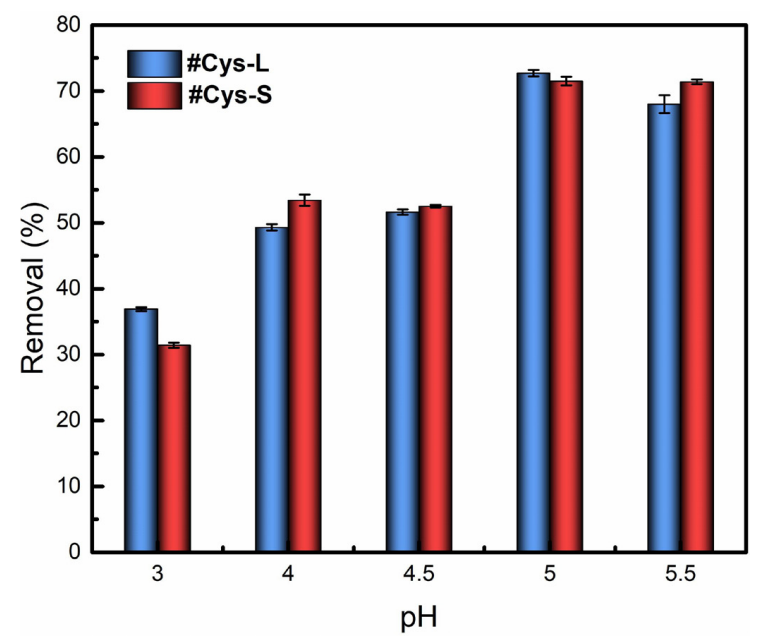

Figure 6. Influence of $\mathrm{pH}$ on $\mathrm{Pb}(\mathrm{II})$ removal. The adsorption tests were performed for $2.5 \mathrm{mg} / \mathrm{L}$ of $\mathrm{Pb}$ (II) solution, contact time of 240 minutes and at $25^{\circ} \mathrm{C}$. 
the fitting with PFO and PSO models are listed in Table 2. According to the correlation coefficient and to the MAPE, the PSO best describes the kinetics of the adsorption process under the used experimental conditions. In the framework of this model, the characteristic of the kinetic curves was determined through the approaching equilibrium factor $\left(R_{w}\right)$ according to:

$$
R_{w}=\frac{1}{1+q_{e} k_{2} t_{r e f}},
$$

where $t_{\text {ref }}$ is the longest operation time based on the kinetic experiments for each sample. The $R_{w}$ values found for both samples lied in the range of $0.1-0.01$, which is typical of largely curved kinetic curves and well approaching equilibrium $^{64}$. The comparative kinetic performance of the samples can be deduced from their 2nd-order rate index $\left(q_{e} k_{2}\right)$, which is closely related to the particle size for adsorption experiments conducted in the same general conditions, such as $\mathrm{pH}$, ionic strength, temperature, and target adsorbate. In the present study, the nanopowder sample based on larger nanoparticles has a higher 2 nd-order rate index, therefore better kinetic performance for general operation. This result indicates that the larger nanoparticles have a higher number of active surface sites leading to a faster adsorption rate and a shorter equilibrium time. The kinetic behavior of the $\mathrm{CoFe}_{2} \mathrm{O}_{4} @ \mathrm{\gamma}_{\mathrm{\gamma}}-\mathrm{Fe}_{2} \mathrm{O}_{3} @$ Cys nanoparticles on $\mathrm{Pb}$ (II) adsorption is similar to that of $\mathrm{CoFe}_{2} \mathrm{O}_{4}, \mathrm{NiFe}_{2} \mathrm{O}_{4}, \mathrm{ZnFe}_{2} \mathrm{O}_{4}$ and $\mathrm{Fe}_{3} \mathrm{O}_{4}$ magnetic nanoparticles ${ }^{20,65}$.

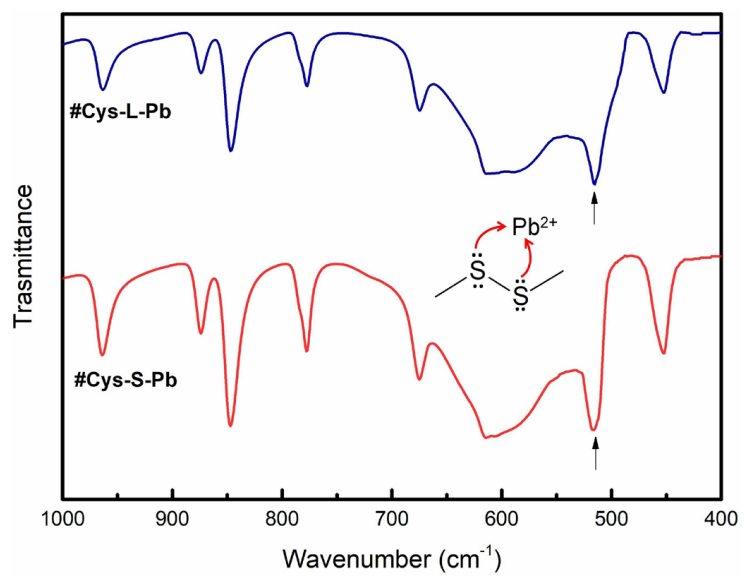

Figure 7. FTIR spectra of the nanopowder samples after loading with $\mathrm{Pb}(\mathrm{II})$ at $\mathrm{pH}$ 3. The shift of the $\mathrm{S}-\mathrm{S}$ stretching band from 540 $\mathrm{cm}^{-1}$ to around $516 \mathrm{~cm}^{-1}$ indicates that the lead adsorption occurs through the thioether group of cystine at this $\mathrm{pH}$ region.

\subsection{Adsorption isotherms}

The fitting of the adsorption data with the linearized form of the Langmuir model is shown in Figure 9 and the corresponding obtained parameters are listed in Table 3. The good agreement with this model suggests monolayer adsorption and homogeneous distribution of the surface sites. The calculated values of $R_{L}$ lied in the range of $0-1$, indicating that the adsorption of $\mathrm{Pb}$ (II) by the $\mathrm{CoFe}_{2} \mathrm{O}_{4} @ \mathrm{\gamma}$ $\mathrm{Fe}_{2} \mathrm{O}_{3} @$ Cys nanoparticles is favorable ${ }^{66}$. According to the fitting results, the nanopowder samples exhibited very close values of maximum adsorption capacity, indicating that the nanoparticle mean size is not a relevant parameter to the removal capacity of the samples. The similar adsorption
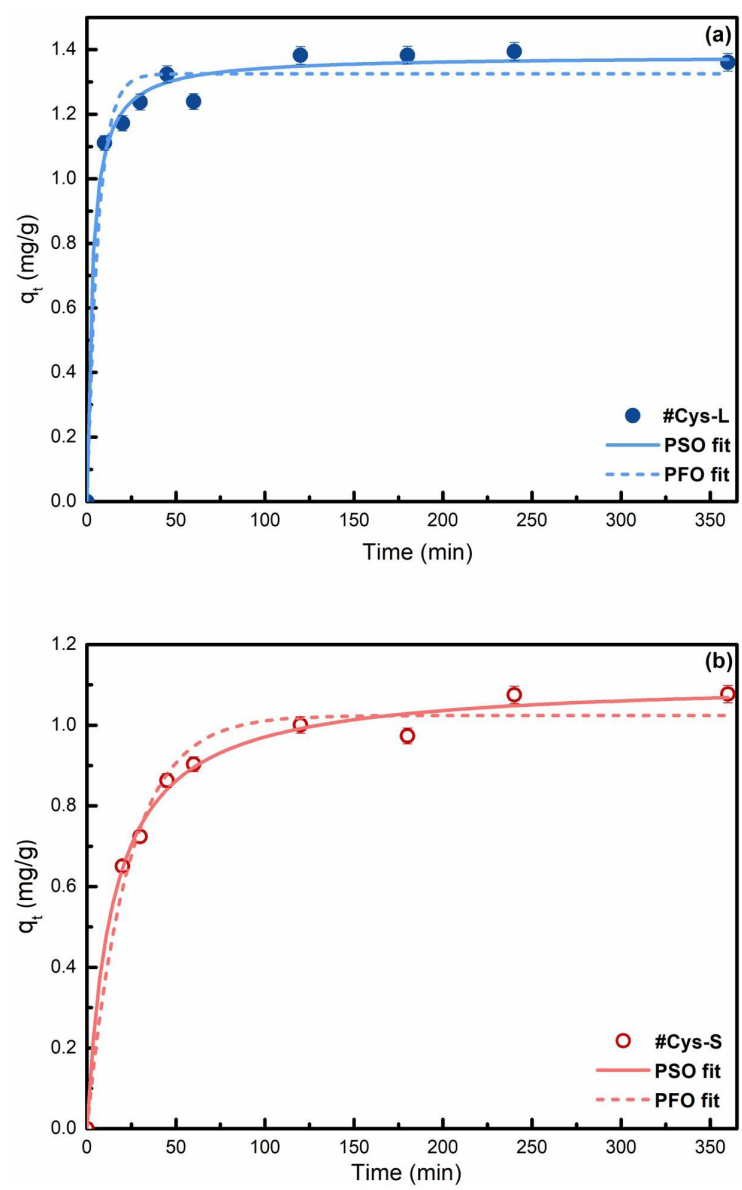

Figure 8. Kinetic data of $\mathrm{Pb}(\mathrm{II})$ adsorption by samples \#Cys-L (a) and \#Cys-S (b) fitted using pseudo-first-order (PFO) and pseudosecond-order (PSO) models. The results were obtained for initial $\mathrm{Pb}$ (II) concentration of $2.5 \mathrm{mg} / \mathrm{L}$ at $\mathrm{pH} 5$.

Table 2. Kinetic parameters obtained from the fittings with the PFO and PSO models.

\begin{tabular}{|c|c|c|c|c|c|c|c|c|c|c|}
\hline \multirow[b]{2}{*}{ Sample } & \multicolumn{4}{|c|}{ Pseudo-first-order } & \multicolumn{5}{|c|}{ Pseudo-second-order } & \multirow[b]{2}{*}{$\begin{array}{c}\text { MAPE } \\
(\%)\end{array}$} \\
\hline & $k_{1}\left(\min ^{-1}\right)$ & $q_{e}(\mathrm{mg} / \mathrm{g})$ & $R^{2}$ & $\begin{array}{c}\text { MAPE } \\
(\%)\end{array}$ & $\begin{array}{c}k_{2}(\mathrm{~g} / \mathrm{min} \\
\mathrm{mg})\end{array}$ & $q_{e}(\mathrm{mg} / \mathrm{g})$ & $\boldsymbol{R}_{w}$ & $\begin{array}{c}q_{e} k_{2} \\
\left(m^{-1} n^{-1}\right)\end{array}$ & $\mathbf{R}^{2}$ & \\
\hline \#Cys-L & $0.16 \pm 0.03$ & $1.33 \pm 0.03$ & 0.972 & 4.2 & $0.25 \pm 0.05$ & $1.38 \pm 0.02$ & 0.024 & 0.345 & 0.991 & 2.4 \\
\hline \#Cys-S & $0.04 \pm 0.01$ & $1.02 \pm 0.02$ & 0.982 & 4.0 & $0.06 \pm 0.01$ & $1.11 \pm 0.02$ & 0.059 & 0.067 & 0.993 & 2.3 \\
\hline
\end{tabular}


Table 3. The fitted parameters for $\mathrm{Pb}(\mathrm{II})$ adsorption using the linearized Langmuir model.

\begin{tabular}{cccccc}
\hline Sample & $K_{L}(\mathrm{~L} / \mathrm{mg})$ & $q_{\max }(\mathrm{mg} / \mathrm{g})$ & $R_{L}$ & $\mathrm{R}^{2}$ & MAPE (\%) \\
\hline \#Cys-L & $24.0 \pm 1.1$ & $1.16 \pm 0.03$ & $0.02-0.002$ & 0.999 & 6.8 \\
\hline \#Cys-S & $10.6 \pm 0.8$ & $1.11 \pm 0.03$ & $0.05-0.005$ & 0.980 & 16.2 \\
\hline
\end{tabular}

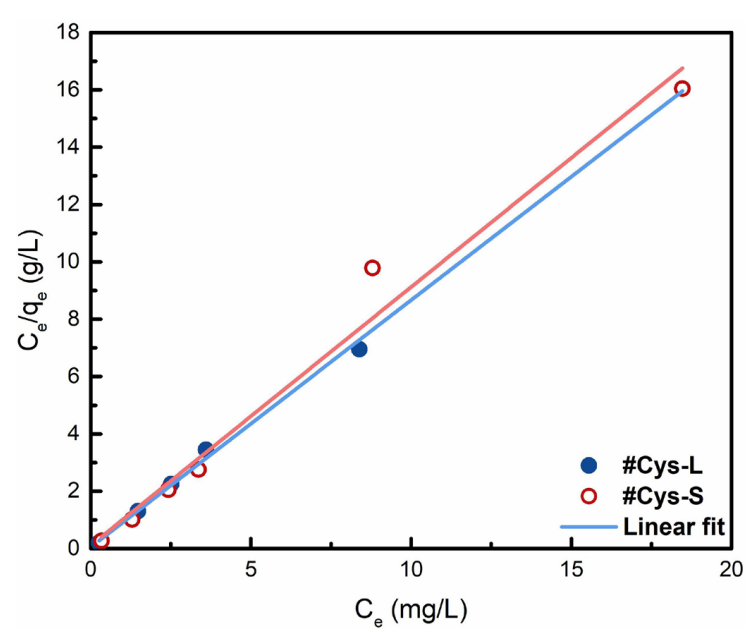

Figure 9. Adsorption data at $\mathrm{pH} 5$ fitted with the linearized form of the Langmuir model.

performance of the samples can be related to the close values of zeta potential of the nanoparticles of both samples at $\mathrm{pH}$ 5 (Figure 5). However, the larger $K_{L}$ value of the sample \#Cys-L suggests that the $\mathrm{Pb}(\mathrm{II})$ ions have higher affinity for the nanoparticles with larger mean size, which agrees with their better kinetic performance.

The maximum adsorption capacities of the proposed nanoparticles at $\mathrm{pH} 5$ are significantly lower than that of $\mathrm{Fe}_{3} \mathrm{O}_{4}$ nanoparticles $(29 \mathrm{mg} / \mathrm{g} \text {, at } \mathrm{pH} 5.5)^{20}$. However, magnetite based nanoparticles present low resistance of oxidation, which clearly shorts their life-cycle in real applications. Other ferrite-based nanoparticles such as $\mathrm{CoFe}_{2} \mathrm{O}_{4}, \mathrm{NiFe}_{2} \mathrm{O}_{4}$ and $\mathrm{ZnFe}_{2} \mathrm{O}_{4}$ also exhibit higher values of maximum adsorption capacity $(9.34 \mathrm{mg} / \mathrm{g}, 17.76 \mathrm{mg} / \mathrm{g}$ and $20.58 \mathrm{mg} / \mathrm{g}$, respectively) in batch studies at $\mathrm{pH} 2^{65}$. In this case, even though the good adsorption performance of the nanomaterials, the process requires strong $\mathrm{pH}$ adjustments, which is a drawback for real applications since the final $\mathrm{pH}$ of the treated effluent must be in the range of 6-9 to meet the standards of the Global Effluent Guidelines ${ }^{67}$. In this general context, the application of the proposed nanopowders represent a feasible alternative since they present long-term stability, do not require critical $\mathrm{pH}$ adjustments, and are elaborated using low cost and widely available materials.

\subsection{Regeneration and reusability}

Based on the effect of $\mathrm{pH}$ on the adsorption capacity of the nanopowders, desorption tests were carried out by washing the $\mathrm{Pb}$ (II)-loaded nanoparticles with $\mathrm{NaOH}$ solution, as described in section 2.5. Increasing $\mathrm{pH}$ to alkaline medium leads to desorption of lead ions and their precipitation as $\mathrm{Pb}(\mathrm{OH})_{2}$. Figure 10 shows that the removal performance of the regenerated nanoparticles in readsorption experiments

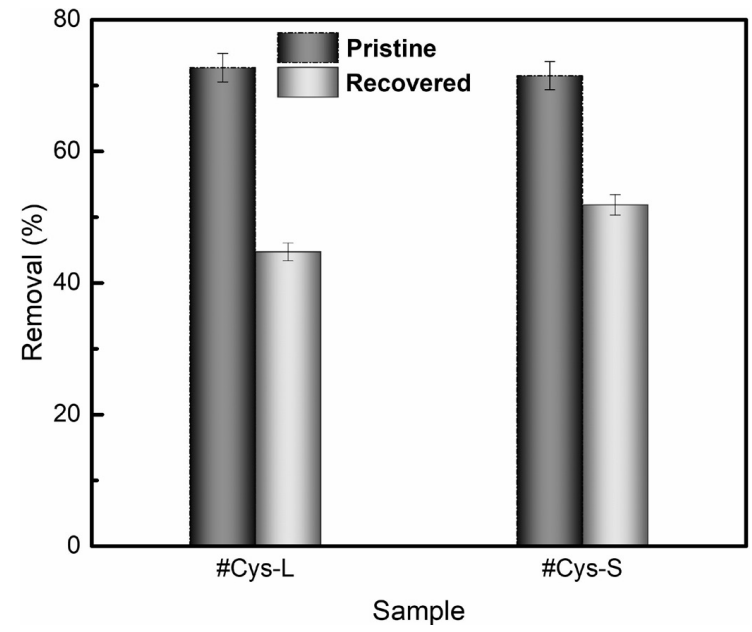

Figure 10. Comparative of removal percentage of pristine and recovered nanoparticles.

decreases compared to the pristine ones. It may be related to the detachment of some cysteine/cystine molecules from surface and to the affinity of $\mathrm{Pb}(\mathrm{OH})_{3}{ }^{-}$ions, formed during the washing process, for nanoparticle surface, which reduces the number of available sites for $\mathrm{Pb}$ (II) readsorption. Anyway, from the reusability point of view, the regenerated nanoparticles of samples \#Cys-L and \#Cys-S retained around 62 and 73\% of their adsorption capacity, respectively, suggesting that the prepared nanopowders can be used repeatedly in real operation conditions. The better performance of sample \#Cys-S can be related to more efficient desorption of lead ions through the washing procedure leading to regenerated nanoparticles with more available sites for readsorption cycles.

\section{Conclusions}

The present study reported on the synthesis of cysteineferrite-based magnetic nanopowders of two different mean sizes and their application for $\mathrm{Pb}$ (II) removal from water. The nanopowders present long-term stability and were elaborated using widely available and low-cost supplies. The physicochemical characterization confirmed the magnetic responsibility of the nanopowders and their core@shell profile, where the cysteine molecules attach the surface of the nanoparticles via the formation of $\mathrm{Fe}-\mathrm{S}$ bonding. The results of structure characterization also show that the functionalization implies the formation cystine, bonded to the nanoparticle surface via carboxylate groups. The applicability of the nanopowders was investigated from batch studies under different experimental conditions. The adsorption data exhibited good compliance with the Langmuir model, suggesting monolayer adsorption. The kinetic data were fitted well by the Pseudo-second-order model with the best 
equilibrium time of $2 \mathrm{~h}$. The nanoparticle mean size did not significantly affect the adsorption capacity. However, the nanopowder sample based on larger nanoparticles showed a better kinetic performance. The $\mathrm{pH}$ of the medium played an important role in the adsorption capacity and the mechanism of lead uptake. The optimal condition was found in $\mathrm{pH} 5-6$, which is related to the favorable electrostatic interaction between the surface groups and the $\mathrm{Pb}$ (II) cationic forms. This optimal $\mathrm{pH}$ range is advantageous for real-life applications since it does not require strong $\mathrm{pH}$ adjustments to meet international standards. In low $\mathrm{pH}$ regions, the adsorption mechanism mainly involves hard-soft-acid-base interaction between $\mathrm{Pb}^{2+}$ ions and thioether groups. After regeneration, the nanopowders retained more than $60 \%$ of their adsorption capacity, showing that they are potentially reusable. Finally, from the present study, the proposed nanopowders can be considered a feasible promise to remove $\mathrm{Pb}(\mathrm{II})$ and other related toxic metals from water with magnetic assistance.

\section{Acknowledgements}

Authors gratefully acknowledge the financial support of the Brazilian agencies: The Coordination for the Improvement of Higher Education Personnel (CAPES), the National Council for Scientific and Technological Development (CNPq) [grant number 400849/2016-0], the National Institute of Science and Technology Complex Fluids (INCT-FCx) and the Distrito Federal Research Foundation (FAP-DF) [grant numbers 0193.001569/2017 and 0193.001194/2016].

\section{References}

1. Granados-Correa F, Serrano-Gómez J. Removal of chromium hexavalent ions from aqueous solution by retention onto iron phosphate. J Chil Chem Soc. 2010;55(3):312-6.

2. Naiya TK, Bhattacharya AK, Das SK. Adsorption of Cd(II) and $\mathrm{Pb}$ (II) from aqueous solutions on activated alumina. J Colloid Interface Sci. 2009;333(1):14-26.

3. Karami H. Heavy metal removal from water by magnetite nanorods. Chem Eng J. 2013;219:209-16.

4. Elouear Z, Bouzid J, Boujelben N, Feki M, Jamoussi F, Montiel A. Heavy metal removal from aqueous solutions by activated phosphate rock. J Hazard Mater. 2008;156(1-3):412-20.

5. Wang XS, Zhu L, Lu HJ. Surface chemical properties and adsorption of $\mathrm{Cu}$ (II) on nanoscale magnetite in aqueous solutions. Desalination. 2011;276(1-3):154-60.

6. Zhang Y, Yan L, Xu W, Guo X, Cui L, Gao L, et al. Adsorption of $\mathrm{Pb}$ (II) and $\mathrm{Hg}$ (II) from aqueous solution using magnetic $\mathrm{CoFe}_{2} \mathrm{O}_{4}$-reduced graphene oxide. J Mol Liq. 2014;191:177-82.

7. Günay A, Arslankaya E, Tosun I. Lead removal from aqueous solution by natural and pretreated clinoptilolite: adsorption equilibrium and kinetics. J Hazard Mater. 2007;146(1-2):36271.

8. WHO: World Health Organization. Guidelines for drinking water quality. Geneva: WHO; 2011.

9. Ahmed MA, Ali SM, El-Dek SI, Galal A. Magnetite-hematite nanoparticles prepared by green methods for heavy metal ions removal from water. Mater Sci Eng B: Solid-State Mater Adv Technol. 2013;178(10):744-51.

10. Chen Q, Luo Z, Hills C, Xue G, Tyrer M. Precipitation of heavy metals from wastewater using simulated flue gas: sequent additions of fly ash, lime and carbon dioxide. Water Res. 2009;43(10):2605-14.

11. Naushad M, ALOthman ZA. Separation of toxic $\mathrm{Pb}^{2+}$ metal from aqueous solution using strongly acidic cation-exchange resin: analytical applications for the removal of metal ions from pharmaceutical formulation. Desalination Water Treat. 2015;53(8):2158-66.

12. Naushad M, ALOthman ZA, Awual MR, Alam MM, Eldesoky GE. Adsorption kinetics, isotherms, and thermodynamic studies for the adsorption of $\mathrm{Pb}^{2+}$ and $\mathrm{Hg}^{2+}$ metal ions from aqueous medium using Ti(IV) iodovanadate cation exchanger. Ionics. 2015;21(8):2237-45.

13. Al-Rashdi BAM, Johnson DJ, Hilal N. Removal of heavy metal ions by nanofiltration. Desalination. 2013;315:2-17.

14. Santos ICA, Santos IO, Pontual LV, Monteiro LPC, Mainier FB. Electrolytic removal of Cadmium, Lead and Copper from Wastewater. J Environ Prot. 2016;7(5):699-704.

15. Lin L, Xu X, Papelis C, Cath TY, Xu P. Sorption of metals and metalloids from reverse osmosis concentrate on drinking water treatment solids. Separ Purif Tech. 2014;134:37-45.

16. Kokare A, Suryavanshi V, Zanje S, Kore G, Anuse M. Liquid-liquid extraction and separation of lead(II) by using $\mathrm{N}$-n-octylcyclohexylamine as an extractant: analysis of real samples. Anal Methods. 2016;8(32):6158-67.

17. Awwad AM, Farhan AM. Equilibrium, Kinetic and Thermodynamics of biosorption of Lead (II) Copper (II) and Cadmium (II) Ions from aqueous solutions onto olive leaves powder. American Journal of Chemistry. 2012;2(4):238-44.

18. Manawi Y, McKay G, Ismail N, Kayvani Fard A, Kochkodan $\mathrm{V}$, Atieh MA. Enhancing lead removal from water by complexassisted filtration with acacia gum. Chem Eng J. 2018;352:82836.

19. Cheng Z, Tan ALK, Tao Y, Shan D, Ting KE, Yin XJ. Synthesis and characterization of iron oxide nanoparticles and applications in the removal of heavy metals from industrial wastewater. Int J Photoenergy. 2012;2012:608298.

20. Nassar NN. Rapid removal and recovery of $\mathrm{Pb}(\mathrm{II})$ from wastewater by magnetic nanoadsorbents. J Hazard Mater. 2010;184(1-3):538-46.

21. Bée A, Talbot D, Abramson S, Dupuis V. Magnetic alginate beads for $\mathrm{Pb}(\mathrm{II})$ ions removal from wastewater. J Colloid Interface Sci. 2011;362(2):486-92.

22. Campos AFC, Michels-Brito PH, Silva FG, Gomes RC, Gomide G, Depeyrot J. Removal of direct yellow 12 from water using CTAB-coated core-shell bimagnetic nanoadsorbents. J Environ Chem Eng. 2019;7(2):103031.

23. Yang JC, Yin XB. CoFe2 O4 @MIL-100(Fe) hybrid magnetic nanoparticles exhibit fast and selective adsorption of arsenic with high adsorption capacity. Sci Rep. 2017;7:1-15.

24. Sangeetha J, Philip J. Synthesis, characterization and antimicrobial property of $\mathrm{Fe}_{3} \mathrm{O}_{4}$-Cys-HNQ nanocomplex, with 1-cysteine molecule as a linker. RSC Advances. 2013;3(21):8047-57.

25. Tan $\mathrm{Y}$, Chen $\mathrm{M}$, Hao Y. High efficient removal of $\mathrm{Pb}$ (II) by amino-functionalized $\mathrm{Fe}_{3} \mathrm{O}_{4}$ magnetic nano-particles. Chem Eng J. 2012;191:104-11.

26. Giles NM, Watts AB, Giles GI, Fry FH, Littlechild JA, Jacob C. Metal and redox modulation of cysteine protein function. Chem Biol. 2003;10:677-93.

27. Rebodos RL, Vikesland PJ. Effects of oxidation on the magnetization of nanoparticulate magnetite. Langmuir. 2010;26(22):16745-53.

28. Gómez-Pastora J, Bringas E, Ortiz I. Recent progress and future challenges on the use of high performance magnetic nano-adsorbents in environmental applications. Chem Eng J. 2014;256:187-204.

29. Campos AFC, Oliveira HAL, Silva FN, Silva FG, Coppola $\mathrm{P}$, Aquino R, et al. Core-shell bimagnetic nanoadsorbents for hexavalent Chromium removal from aqueous solutions. J Hazard Mater. 2019;362:82-91.

30. Tourinho FA, Franck R, Massart R. Aqueous ferrofluids based on manganese and cobalt ferrites. J Mater Sci. 1990;25(7):324954.

31. Sousa MH, Tourinho FA, Depeyrot J, Silva GJ, Lara MCFL. New electric double-layered magnetic fluids based on Copper, Nickel, and Zinc ferrite nanostructures. J Phys Chem B. 2001;105(6):1168-75. 
32. Aquino R, Tourinho FA, Itri R, Lara MCFL, Depeyrot J. Size control of $\mathrm{MnFe} 2 \mathrm{O} 4$ nanoparticles in electric double layered magnetic fluid synthesis. J Magn Magn Mater. 2002;252(1-3):235.

33. Gomes JA, Sousa MH, Tourinho FA, Aquino R, Depeyrot J, Dubois E, et al. Synthesis of core-shell ferrite nanoparticles for ferrofluids: chemical and magnetic analysis. J Phys Chem C. 2008;112:6220-7.

34. Martins FH, Silva FG, Paula FLO, Juliano AG, Aquino R, Mestnik J Fo, et al. Local structure of core-shell $\mathrm{MnFe}_{2} \mathrm{O}_{4+\delta}{ }^{-}$ based nanocrystals: cation distribution and valence states of manganese ions. J Phys Chem C. 2017;121(16):8982-91.

35. Pilati V, Cabreira Gomes R, Gomide G, Coppola P, Silva FG, Paula FLO, et al. Core/shell nanoparticles of non-stoichiometric $\mathrm{Zn}-\mathrm{Mn}$ and $\mathrm{Zn}-\mathrm{Co}$ ferrites as thermosensitive heat sources for magnetic fluid hyperthermia. J Phys Chem C. 2018;122(5):302838.

36. Moreira AFL, Paula FLO, Campos AFC, Depeyrot J. Local structure investigation of cobalt ferrite-based nanoparticles by synchrotron X-ray diffraction and absorption spectroscopy. J Solid State Chem. 2020;286:121269.

37. Gawande MB, Velhinho A, Nogueira ID, Ghumman CAA, Teodoro OMND, Branco PS. A facile synthesis of cysteine-ferrite magnetic nanoparticles for application in multicomponent reactions - a sustainable protocol. RSC Advances. 2012;2(15):6144-9.

38. Bhattacharjee S. DLS and zeta potential - what they are and what they are not? J Control Release. 2016;235:337-51.

39. Foo KYF, Hameed BH. Insights into the modeling of adsorption isotherm systems. Chem Eng J. 2010;156:2-10.

40. Sarma GK, Sen Gupta S, Bhattacharyya KG. Nanomaterials as versatile adsorbents for heavy metal ions in water: a review. Environ Sci Pollut Res Int. 2019;26(7):6245-78.

41. Tran HN, You SJ, Hosseini-Bandegharaei A, Chao HP. Mistakes and inconsistencies regarding adsorption of contaminants from aqueous solutions: a critical review. Water Res. 2017;120:88116.

42. William Kajjumba G, Emik S, Öngen A, Kurtulus Özcan H, Aydın S. Modelling of adsorption kinetic processes-errors, theory and application. In: Edebali S, editor. Advanced Sorption Process Applications. London: IntechOpen; 2019

43. Debrassi A, Baccarin T, Demarchi CA, Nedelko N, ŚlawskaWaniewska A, Dluzewski P, et al. Adsorption of remazol red 198 onto magnetic N-lauryl chitosan particles: equilibrium, kinetics, reuse and factorial design. Environ Sci Pollut Res Int. 2012;19(5):1594-604

44. Guerra AAAM, Campos AFC, Lima RM, Kern C, Gomes F, Gomide G, et al. Efficient uptake of phosphorus from water by core@shell bimagnetic nanoadsorbents. J Environ Chem Eng. 2020;8(4):103888.

45. Oliveira HAL, Campos AFC, Gomide G, Zhang Y, Ghoshal S. Elaboration of a core@shell bimagnetic nanoadsorbent $\left(\mathrm{CoFe}_{2} \mathrm{O}_{4} @ \gamma-\mathrm{Fe}_{2} \mathrm{O}_{3}\right)$ for the removal of $\mathrm{As}(\mathrm{V})$ from water. Colloids Surf A Physicochem Eng Asp. 2020;600:125002.

46. Moggach SA, Allan DR, Parsons S, Sawyer L, Warren JE. The effect of pressure on the crystal structure of hexagonal L-cystine. J Synchrotron Radiat. 2005;12(5):598-607.

47. Silva FG, Aquino R, Tourinho FA, Stepanov VI, Raikher YL, Perzynski $\mathrm{R}$, et al. The role of magnetic interactions in exchange bias properties of $\mathrm{MnFe}_{2} \mathrm{O}_{4} @ \gamma-\mathrm{Fe}_{2} \mathrm{O}_{3}$ core/shell nanoparticles. J Phys D Appl Phys. 2013;46(28):285003.

48. Wolpert M, Hellwig P. Infrared spectra and molar absorption coefficients of the 20 alpha amino acids in aqueous solutions in the spectral range from 1800 to $500 \mathrm{~cm}-1$. Spectrochim Acta A Mol Biomol Spectrosc. 2006;64(4):987-1001.

49. Bagbi Y, Sarswat A, Mohan D, Pandey A, Solanki PR. Lead and chromium adsorption from water using L-Cysteine functionalized magnetite $\left(\mathrm{Fe}_{3} \mathrm{O}_{4}\right)$ nanoparticles. Sci Rep. 2017;7(1):1-15.

50. Ashour RM, Abdel-Magied AF, Abdel-khalek AA, Helaly OS, Ali MM. Preparation and characterization of magnetic iron oxide nanoparticles functionalized by L-cysteine: adsorption and desorption behavior for rare earth metal ions. J Environ Chem Eng. 2016;4(3):3114-21.

51. Dolci S, Ierardi V, Remskar M, Jagličić Z, Pineider F, Boni A, et al. Chemical-physical properties, morphology, and magnetic investigations on new cystine functionalized ultrasmall super-paramagnetic iron-oxide nanoparticles. J Mater Sci. 2013;48(3):1283-91.

52. Vieira AP, Berndt G, Souza IG Jr, Mauro E, Paesano A, Santana $\mathrm{H}$, et al. Adsorption of cysteine on hematite, magnetite and ferrihydrite: FT-IR, Mössbauer, EPR spectroscopy and X-ray diffractometry studies. Amino Acids. 2011;40(1):205-14.

53. Abdou JM, Seidel P, Sterrer M. Bonding and thermal stability of cysteine on single-crystalline iron oxide surfaces and $\mathrm{Pt}(111)$. J Chem Phys. 2020;152(6):064701.

54. Figueredo F, Saavedra A, Cortón E, Diz V. Hydrophobic forces are relevant to bacteria-nanoparticle interactions: pseudomonas putida capture efficiency by using Arginine, Cysteine or Oxalate wrapped magnetic nanoparticles. Colloids and Interfaces. 2018;2(3):29.

55. Marickar YMF, Lekshmi PR, Varma L, Koshy P. Problem in analyzing cystine stones using FTIR spectroscopy. Urol Res. 2009;37(5):263-9.

56. Ramachandran E, Natarajan S. Crystal growth of some urinary stone constituents: III. In- vitro crystallization of L-cystine and its characterization. Cryst Res Technol. 2004;39(4):308-12.

57. Edsall JT, Otvos JW, Rich A. Raman spectra of amino acids and related compounds. VII. Glycylglycine, Cysteine, Cystine and Other Amino Acids. J Am Chem Soc. 1950;72(1):474-7.

58. Van Wart HE, Scheraga HA. Raman spectra of cystine-related disulfides. Effect of rotational isomerism about carbon-sulfur bonds on sulfur-sulfur stretching frequencies. J Phys Chem. 1976;80(16):1812-23.

59. Schwaminger SP, García PF, Merck GK, Bodensteiner FA, Heissler S, Günther S, et al. Nature of interactions of amino acids with bare magnetite nanoparticles. J Phys Chem C. 2015;119(40):23032-41.

60. Nara M, Torii H, Tasumi M. Correlation between the vibrational frequencies of the carboxylate group and the types of its coordination to a metal ion: an ab initio molecular orbital study. J Phys Chem. 1996;100(51):19812-7.

61. Gao X, Metge DW, Ray C, Harvey RW, Chorover J. Surface complexation of carboxylate adheres Cryptosporidium parvum oocysts to the hematite-water interface. Environ Sci Technol. 2009;43(19):7423-9.

62. Palacios EG, Juárez-López G, Monhemius AJ. Infrared spectroscopy of metal carboxylates. Hydrometallurgy. 2003;72(1-2):139-48.

63. Yang S, Zhao D, Zhang H, Lu S, Chen L, Yu X. Impact of environmental conditions on the sorption behavior of $\mathrm{Pb}(\mathrm{II})$ in Na-bentonite suspensions. J Hazard Mater. 2010;183(1-3):63240.

64. Wu FC, Tseng RL, Huang SC, Juang RS. Characteristics of pseudo-second-order kinetic model for liquid-phase adsorption: A mini-review. Chem Eng J. 2009;151(1-3):1-9.

65. Vazquez-Olmos AR, Abatal M, Sato-Berru RY, Pedraza-Basulto GK, Garcia-Vazquez V, Sainz-Vidal A, et al. Mechanosynthesis of MFe 2 O 4 ( $\mathrm{M}=\mathrm{Co}, \mathrm{Ni}$, and $\mathrm{Zn}$ ) Magnetic Nanoparticles for $\mathrm{Pb}$ Removal from Aqueous Solution. J Nanomater. 2016;2016:9182024.

66. Ayawei N, Ebelegi AN, Wankasi D. Modelling and interpretation of adsorption isotherms. J Chem. 2017;2017:3039817.

67. Levi Strauss \& Co. Appendix V: Global effluent guidelines. EHSH. 2007;1(2):141-74. 